\title{
Programa Científico
}

\section{NECESSIDADE PSICO ESPIRITUAL DO PACIENTE}

\author{
Pe. Ivo Gelain *
}

\section{I - Introdução}

Proponho-me apresentar reflexão sobre um dos assuntos discutíveis e discutidos atualmente: a necessidade psíco-espiritual do paciente e seu atendimento.

As reflexões pretendem referir-se à existência, conceituação da necessidade psíco-espiritual, suas possiveis semelhanças com as necessidades psicológicas do paciente.

Pretendem, também, referir-se às maneiras de manifestação e às formas de atendimento da necessidade psíco-espiritual.

O problema, sem dúvida, depende da constatação da necessidade espiritual, sua conceituação, sua posição no conceito de homem integral, sua situação frente ao atendimento integral, a responsabilidade e responsabilização da equipe de saúde, em especial da enfermagem, no atendimento da necessidade em questão.

\section{II - A Necessidade Psico-Espiritual no Homem}

Quando se fala em homem, entende-se, logicamente o ser humano nos seus diferentes níveis: psico-biológico, psíco-social, psícoespiritual.

Cada um desses níves apresenta, como sabemos, suas tendências, suas necessidades.

Assim, podemos observar e sentir no nível psíco-biológico a tendência da auto-conservação, a necessidade de alimento, de oxigênio, etc.

No nível psíco-social depara-se o ser humano com as necessidades de segurança, auto-afirmação, aprovação, liberdade, auto-realização, etc.

* Enfermeiro - Capelão do Hospital do Servidor Público do Estado de São Paulo e colaborador da Cadeira de Etica da Escola Paulista de Enfermagem. 
No nível psíco-espiritual, encontra-se o homem com uma série de aspirações, questionamentos, problemáticas que, freqüentemente o fazem parar para refletir e indagar.

Questiona-se o homem sobre sua essência, sua natureza, seu destino, sua vida no além morte.

Questiona o sentido da vida, a procedência e o destino do mundo.

Indaga o porquê do sofrimento, das desgraças, das catástrofes, das infelicidades.

Constata em si um profundo desejo do infinito.

Busca a conceituação, o encontro e a vivência da felicidade.

Percebe e sente que estes questionamentos estão presentes da caverna ao arranhacéu, do analfabeto ao mais culto, embora as respostas sejam diferentes de acordo com as condições sócio-econômicas e culturais dos indivíduos.

A tendência ao religioso está tão presente e profunda no homem como a da conservação. Está no fundamento da natureza humana.

Constatam os psicanalistas, os etnólogos, os sociólogos que o impulso para o transcedente é natural, fisiológico, universal. Concluem que não há ser humano na terra que não aspire ao trancedente, que não se questione, a seu modo, sobre o problema espiritual, religioso.

Ensina a experiência universal que é um sentimento tão inato no homem, capaz de levá-lo a preferir a insegurança ao conforto, a agrura à tranqüilidade, o medo ao apoio, a morte à vida se o preço de tudo isto for pretender acorrentá-lo.

É tão forte que se impõe aos instintos biológicos, até mesmo ao instinto da conservação.

E necessário lembrar, todavia, que não é uma tendência biológica ou zoológica apenas. Pelo que consta, só o homem possui aspiração ao espiritual, ao ético, ao teologal.

São estas tendências que marcam o homem, são próprias da natureza humana. São, conforme Lerch, "Aspirações metafísicas da natureza humana".

Torna-se, todavia necessário não identificar nem confundir o aspecto religioso, espiritual com 0 aspecto puramente psicológico da pessoa humana.

Embora a tendência à transcedência se situe na esfera psicológica, dela se diferencia, pois, se por um lado o que é religioso tem caracteres psicológicos, por outro, nem tudo o que é psicológico tem conotação religiosa, espiritual.

0 aspecto religioso relaciona-se com o transcendente, com o sobrenatural, com o espiritual. 
O aspecto psicológico relaciona-se com o comportamento humano, quer nas manifestações psíquicas, quer em suas atitudes observáveis.

Ambos os aspectos, todavia, mantêm uma intercomunicação profunda.

Dar atendimento psicológico não significa, por si, dar atendimento religioso, espiritual. A recíproca, porém, em muitos casos e aspectos pode ser verdadeira.

Para haver atendimento espiritual, há necessidade de ser o homem atingido e atendido na problemática referente às respostas aos questionamentos de constatação transcendente.

\section{III - Manifestação e Atendimento da Necessidade Psico-Espi- ritual}

Atendimento psíco-espiritual abrange o atendimento das tendências que levam o ser humano a buscar uma significação do seu agir dentro de sua esfera e o impulsiona para além do mundo limitado.

Há no homem uma fome metafísica que somente o Absoluto poderá saciar. Fome metafísica manifestada das mais variadas formas.

- Pela presença de angústia de fundo espiritual.

interessante neste sentido o testemunho do psicólogo e médico terapeuta Carl Gustav Jung: "Entre todos os meus doentes na segunda metade da vida, isto é, tendo mais de 35 anos, não houve um só cujo problema mais profundo não fosse constituído pela questão de sua atitude religiosa.

Todos, em última análise estavam doentes por terem perdido aquilo que uma religião viva sempre deu em todos os tempos a seus adeptos e nenhum curou-se realmente sem recobrar a atitude religiosa que the fosse própria".

Isto, é claro, não depende absolutamente de adesão a um credo particular ou de tornar-se membro de uma Igreja:

- Pela apresentação de temor baseado nos questionamentos ainda não respondidos;

- Pelas dúvidas de conotação transcendente;

- Pelas expectativas em função do sobrenatural;

- Pela sede de saber na área espiritual;

- Pela sede de diálogo na esfera espiritual;

- Pela sede de leitura no campo espiritual.

f bom lembrar, ainda, que a reação do ser humano frente ao problema religioso é variável. 
Há indivíduos que se dizem ateus, não crêem em Deus nem em valores espirituais. Estes, também, deparam-se com freqüência com os questionamentos já analisados.

Há os sem religião: os que crêem em. Deus, nos valores espirituais, mas, não aderem a credo algum.

Encontramos os indiferentes, isto é, nominalmente aderem a um credo, mas, não o praticam.

Há finalmente, os militantes: pertencem a um determinado credo, praticam-no, colaboram e se engajam em determinada atividade de caráter espiritual.

Todos e das mais variadas formas apresentam necessidade do espiritual e interesse por ele.

Estarão recebendo atendimento psíco-espiritual desde que sejam atendidos nas tendências que os levam a buscar uma significação do seu agir.

Dar atendimento psíco-espiritual, portanto, é:

- saciar, da melhor forma possível sua fome metafísica;

- saber atender e analisar o problema;

- saber ouvir os questionamentos, as dúvidas, as angústias;

- conhecer o campo espiritual para não fugir quando solicitados ou quando for detectado o problema;

- dialogar sobre o assunto;

- mostrar compreensão e interesse por este problema, no outro;

- providenciar meios para o atendimento;

- não transferir problemas de ordem espiritual;

- estar atentos a qualquer manifestação do problema.

IV - Atendimento Psico-Espiritual, Parte Integrante do Atendimento Integral.

A equipe de saúde deve, hoje, ser formada por profissionais capazes de demonstrar compreensão das necessidades básicas do ser humano e do indivíduo como um todo, como uma unidade.

Deve ser integrada por profisisonais que atendam integralmente o paciente.

Eis a grande pergunta: Está a equipe de saúde e, em especial, a Enfermagem, na equipe de saúde, atendendo esta necessidade básica do paciente?

Há real preocupação do pessoal de Enfermagem em identificar e compreender, analisar e resolver os problemas de ordem espiritual do paciente?

Estão as Escolas de Enfermagem preparando profissionais que se preocupem seriamente com este aspecto? 
A melhor resposta deverá vir dos próprios pacientes e para tanto foram ouvidos.
V - Resultado da Opiniāo de Pacientes quanto ao Atendimento de Suas Necessidades Psico-Espirituais pelos Profissionais de Enfermagem.

\section{Objetivos:}

Saber dos pacientes, sua opinião sobre o atendimento religioso. psíco-espiritual que lhes é prestado.

\section{Tipo de Hospital:}

Os hospitais foram selecionados visando à maior variedade possível de pacientes: indigentes; I.N.P.S.; I.A.M.S.P.E.; Funrural; Particular.

Foi preparado e aplicado um questionário a 100 (cem) pacientes hospitalizados em 7 (sete) hospitais de São Paulo.

Condições do paciente:

O paciente a ser abordado deveria estar internado há, pelo menos, uma semana.

Questionário:

O questionário adotado foi o seguinte:

1 - Identificação do Paciente:

1.1. - Idade

\begin{tabular}{|c|c|c|c|}
\hline 10 & a 20 & anos & 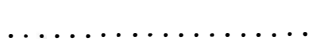 \\
\hline 21 & a 30 & anos & $\cdots \cdots$ \\
\hline 31 & a 40 & anos & \\
\hline 41 & a 50 & anos & \\
\hline 51 & a 60 & anos & \\
\hline 61 & a 70 & anos & \\
\hline 71 & a 80 & anos & \\
\hline
\end{tabular}

1.2. - Sexo

Masculino $\ldots \ldots \ldots \ldots \ldots \ldots \ldots \ldots$

Feminino $\ldots \ldots \ldots \ldots \ldots \ldots \ldots \ldots$ 
1.3. - Religião

Católicos $\ldots \ldots \ldots \ldots \ldots \ldots \ldots \ldots \ldots \ldots \ldots$

Protestantes $\ldots \ldots \ldots \ldots \ldots \ldots \ldots \ldots$ 19\%

Outros .................... $8 \%$

1.4. - Estado Civil

Casados .................. $52 \%$

Solteiros $\ldots \ldots \ldots \ldots \ldots \ldots \ldots \ldots . \ldots \ldots$

Viúvos $\ldots \ldots \ldots \ldots \ldots \ldots \ldots \ldots \ldots$

Outros $\ldots \ldots \ldots \ldots \ldots \ldots \ldots \ldots$

1.5. - Grau de instrução

Primário completo ........... $50 \%$

Ginásio .................. $17 \%$

Colegial .................. $6 \%$

Universitários $\ldots \ldots \ldots \ldots \ldots \ldots \ldots$ 4\%

Analfabetos $\ldots \ldots \ldots \ldots \ldots \ldots \ldots 23 \%$

1.6. - Procedência

São Paulo, Capital ............ $40 \%$

São Paulo, Interior $\ldots \ldots \ldots \ldots \ldots \quad \mathbf{3 0} \%$

Outros Estados ............. $22 \%$

Outros Paises ................. $8 \%$

1.7. - Tipo de Internação

INPS $\ldots \ldots \ldots \ldots \ldots \ldots \ldots \ldots \ldots$

Indigente $\ldots \ldots \ldots \ldots \ldots \ldots \ldots \ldots, \mathbf{3 4 \%}$

IAMSPE $\ldots \ldots \ldots \ldots \ldots \ldots \ldots \ldots \ldots$

Particular $\ldots \ldots \ldots \ldots \ldots \ldots \ldots \ldots 10 \%$

Funrural ................ 1\%

1.8. - Tempo de Internação

10 a 20 dias $\ldots \ldots \ldots \ldots \ldots \ldots \ldots \ldots .54 \%$

21 a 30 dias $\ldots \ldots \ldots \ldots \ldots \ldots \ldots .22 \%$

31 a 40 dias $\ldots \ldots \ldots \ldots \ldots \ldots \ldots . \ldots \ldots$

41 a 50 dias $\ldots \ldots \ldots \ldots \ldots \ldots \ldots \ldots$

51 a 60 dias $\ldots \ldots \ldots \ldots \ldots \ldots \ldots \ldots$

s0 dias .................... $4 \%$

120 dias $\ldots \ldots \ldots \ldots \ldots \ldots \ldots \ldots \ldots$

180 dias $\ldots \ldots \ldots \ldots \ldots \ldots \ldots \ldots \ldots . \ldots \ldots$

400 dias $\ldots \ldots \ldots \ldots \ldots \ldots \ldots \ldots \ldots$ 
II - Questionário

2.1. - Quando ficou doente você pensou:

- No médico .............. $9 \%$

- Em Deus ............... $73 \%$

- Em si, nos seus negócios, nos familiares .............. $13 \%$

- Outras respostas ......... $5 \%$

2.2. - Quando se viu doente e internado:

- Sentiu mais necessidade de rezar $80 \%$

- Sentiu menos necessidade de re-

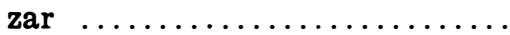

- Ficou indiferente à oração ... $20 \%$

2.3. - Para você, quem cura a doença é:

- O médico com a Medicina .... 6\%

- Deus pela oração do paciente .. $17 \%$

- O médico com a ajuda de Deus $77 \%$

2.4. - Durante sua doença:

- Sentiu necessidade de assistência espiritual ............... 70\%

- Não sentiu necessidade de assistência espiritual .......... 19\%

- Ficou indiferente à assistência espiritual ............ 11\%

2.5. - Durante sua internação:

- Alguém falou com você de assuntos espirituais ......... $32 \%$

- Ninguém falou com você de assuntos espirituais .......... $44 \%$

- As vezes, alguém falou de assuntos espirituais ......... $24 \%$

2.6. - Para você, o atendimento espiritual do paciente é:

- Importante .............. 92\%

- Não é importante .......... $3 \%$

- Indiferente $\ldots \ldots \ldots \ldots \ldots \ldots \ldots$ 
2.7. - Você, alguma vez, perguntou alguma coisa aos funcionários sobre assuntos espirituais?

- Perguntou ................ $\mathbf{4 0 \%}$

- Não perguntou .............60\%

2.8. - Quando você perguntou alguma coisa aos funcionários sobre assuntos espirituais:

- Atenderam-no logo com interesse $70 \%$

- Atenderam-no com desinteresse $25 \%$

- Não o atenderam ............ $5 \%$

2.9. - Durante sua internação, alguma pessoa da enfermagem falou com você sobre assuntos espirituaís?

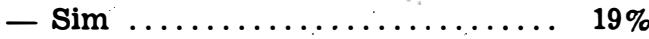

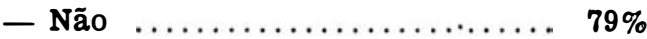

- Sem resposta $\ldots \ldots \ldots \ldots \ldots \ldots . \ldots \ldots$

2.10. - Alguma vez você manifestou no hospital alguma necessidade do atendimento espiritual e esta lhe foi negada?

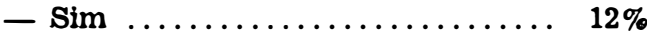

- Não $\ldots \ldots \ldots \ldots \ldots \ldots \ldots \ldots \ldots . \ldots \ldots \%$

- Não manifestaram necessidade . $9 \%$

- Sem resposta $\ldots \ldots \ldots \ldots \ldots \ldots .3 \%$

2.11. - Além do capelão ou do Pastor, quem você acha que deveria interessar-se pelo seu bem espiritual?

- 0 médico $\ldots \ldots \ldots \ldots \ldots \ldots \ldots \ldots .20 \%$

- A enfermeira diplomada ..... $32 \%$

- Os familiares .............. $21 \%$

- Nenhuma das pessoas citadas . $19 \%$

- Todos .................. $\mathbf{8 \%}$

2.12. - Quem, das pessoas abaixo citadas, já lhe deu atendimento espiritual?

- 0 médico $\ldots \ldots \ldots \ldots \ldots \ldots \ldots \ldots .5 \%$

- Enfermeira diplomada ...... $9 \%$

- Familiares ............... $35 \%$

- Atendente ............... $12 \%$

- Nenhuma ............... $39 \%$ 
2.13. - Quanto à prática religiosa você se sente, no hospital:

- Totalmente livre ........... $90 \%$

- Sente pressão dos familiares .. $\mathbf{7 \%}$

- Sente pressão das visitas ...... 2\%

-. Sente pressão dos capelães .... $1 \%$

- Sentre pressão do pesosal de Enfermagem ............... $0 \%$

VI - Conclusões do Resultado da Opinião de Pacientes quanto ao Atendimento de Suas Necessidades psico-espirituais pelos Profissionais da enfermagem.

A ausculta feita entre os pacientes permite concluir que:

6.1. o paciente, ao ficar doente, pensa mais em Deus, nas coisas espirituais do que em si, nos seus negócios, ou no médico;

6.2. o paciente acha que sua cura depende da ajuda de Deus dada ao médico;

6.3. o paciente sente uma grande necessidade de atendimento espiritual;

6.4. o paciente se sente abandonado espiritualmente, pois, a maioria não recebe nenhum apoio espiritual;

6.5. a maioria absoluta dos pacientes, $92 \%$, acha importante 0 atendimento espiritual;

6.6. Durante a internação, $79 \%$ afirma que ninguém lhes dá atendimento espiritual;

6.7. o paciente acha que além do capelão ou do pastor, o médico $(20 \%)$ e a enfermeira $(32 \%)$ deveriam dar-lhe atendimento espiritual;

6.8. o paciente se sente livre na manifestação de sua espiritualidade;

6.9. ao manifestar expressamente sua necessidade espiritual, em geral, é atendido;

$$
\text { VII - Conclusão }
$$

Concluo estas reflexס̄es relembrando que:

7.1. o ser humano e em especial o enfermo, leva consigo uma profunda necessidade psíco-espiritual;

7.2. a necessidade psíco-espiritual faz parte da estrutura da personalidade da pessoa humana; 
7.3. a equipe de Saúde e nesta, a Enfermagem, visa, por objetivo essencial, atender o ser humano em suas necessidades básicas;

7.4. A Enfermagem, na equipe de saúde pela conclusão ausculta à opinião de pacientes e pela constatação, não está atendendo às necessidades psíco-espirituais do paciente.

A Enfermagem, portanto, deverá reconsiderar seriamente $o$ problema e a sua responsabilidade frente à questão, sob pena de ter que redefinir Atendimento Integral do Paciente ou não corresponder $e$ não atingir os objetivos que se propõe.

\section{VIII - Bibliografia}

1. HERDER - $O$ novo Catecismo.

2. MOHANA, João - O mundo e Eu - Agir, Rio de Janeiro, 1963.

3. MOUROUX, Jean - Vocação Cristã do Homem - Flamboyant.

4. REIS. Mário G. - Pessoa - Eficiência e Desenvolvimento, hoje Vozes, Petrópolis, 1969.

5. RINGEL, E. - Psicoterapia au Chevet du Malade in "Presence", 82 (1963) 22.

6. SILVEIRA, Nise da - Jung, Vida e obra - Ed. José de Alvaro - Rio de Janeiro, 1971, pág. 142 - 143.

7. ZILBOORG, Gregory - Psicanálise e Religião - Vozes, Petrópolis, 1969. 